\title{
A study of prevalence of primary hypothyroidism in recently diagnosed type 2 diabetes mellitus in a tertiary care hospital
}

\author{
Sudeb Mukherjee ${ }^{1 *}$, Suhana Datta ${ }^{1}$, Pramathanath Datta ${ }^{2}$, \\ Apurba K. Mukherjee ${ }^{1}$, Indira Maisnam ${ }^{1}$
}

\begin{abstract}
${ }^{1}$ Department of General Medicine, R.G. Kar Medical College, Kolkata-700004, West Bengal, India
${ }^{2}$ Department of Surgery, K. P. C. Medical College, Kolkata-700032, West Bengal, India
\end{abstract}

Received: 05 May 2015

Accepted: 25 May 2015

\section{*Correspondence:}

Dr. Sudeb Mukherjee

E-mail: drsumukherjee@gmail.com

Copyright: () the author(s), publisher and licensee Medip Academy. This is an open-access article distributed under the terms of the Creative Commons Attribution Non-Commercial License, which permits unrestricted non-commercial use, distribution, and reproduction in any medium, provided the original work is properly cited.

\section{ABSTRACT}

Background: The association between thyroid dysfunction and DM has long been recognized, although the prevalence of thyroid dysfunction among diabetes population varies in different studies. This study destined to know the prevalence of thyroid dysfunction of recently diagnosed type 2 diabetes mellitus patients.

Methods: Retrospective chart review of 60 patients with type 2 diabetes mellitus was done. Total 60 patients (male 51, female 9) fulfilling diagnostic criteria for diabetes mellitus according to ADA (American Diabetes Association) criteria were analysed by doing Thyroid Function Test (FT4,TSH).

Results: $75 \%$ of patients have the biochemical features of thyroid dysfunction. Subcategorically in descending order of frequency they are - Subclinical hypothyroidism (33.33\%) (defined by no symptoms or clinical fetures of hypothyroidism but biochemically TSH level in the range of above $5 \mathrm{mIU} / \mathrm{ml}$ but below $10 \mathrm{mIU} / \mathrm{ml}$ with normal FT4 level), $15 \%$ of patients each for overt hypothyroidism (either clinical features or Biochemically TSH $>10 \mathrm{mIU} / \mathrm{ml} \mathrm{or}$ FT4 below normal), and subclinical hyperthyroidism (only biochemical low level of TSH $<0.34 \mathrm{mIU} / \mathrm{ml}$ in this study) and $11.667 \%$ patients show the features of clinical hyperthyroidism (clinical or FT4 level well above normal range along with low TSH).

Conclusions: Avery high prevalence of thyroid dysfunction in this part of world in contrast to Europe \& US suggest routine screening for thyroid disorder in recently diagnosed type 2 diabetes mellitus.

Keywords: DM (Diabetes mellitus), SH (Subclinical hypothyroidism, FT4 (Free levohyroxine), TSH (Thyroid stimulating hormone)

\section{INTRODUCTION}

The worldwide prevalence of DM (Diabetes Mellitus) has risen dramatically over the past two decades, from an estimated 30 million cases in 1985 to 285 million in 2010. Based on current trends, the International Diabetes Federation projects that 552 million individuals will have diabetes by the year 2030. 366 million people have diabetes in 2011. $80 \%$ of people with diabetes live in low- and middle-income countries. The greatest number of people with diabetes are between 40 to 59 years of age. 183 million people $(50 \%)$ with diabetes are undiagnosed. Diabetes caused 4.6 million deaths in. ${ }^{2}$

The prevalence of type $2 \mathrm{DM}$ is rising much more rapidly, presumably because of increasing obesity, reduced activity levels as countries become more industrialized, and the aging of the population. ${ }^{3}$ 
Apart from obesity, genetic factors, metabolic syndrome, environmental factors are also associated with type 2 DM, as are several endocrinopathies.

The association between thyroid dysfunction and DM has long been recognized, although the prevalence of thyroid dysfunction among diabetes population varies in different studies. With insulin and thyroid hormone being intimately involved in cellular metabolism, the excess or deficit of any of them derange the function of another. Variety of thyroid abnormalities may coexist and interact with diabetes mellitus. The hypo- and hyper-functioning thyroid gland influences carbohydrate metabolism at the levels of pancreatic islets and glucose-utilizing target tissues, posing important therapeutic and diagnostic questions. Moreover, thyroidal and islet cells are affected by diseases that are clinically and genetically associated, and where parallel autoimmune pathogenesis is very highly suspected.

Like diabetes, diseases of the thyroid gland are also amongst the most abundant endocrine disorders in the world, second only to diabetes. ${ }^{4}$ Thyroid disorders can have a significant effect on blood glucose levels and, if left untreated, can affect diabetes control. In T2DM the association with thyroid diseases are largely unexplained, although it may relate to old age, and also possibly the fact that some T2DM are actually T1DM patients having a very slow-onset, and so having the same genetic predisposition as T1DM. ${ }^{8}$ Many reports have shown that only clinical assessment might not be able to detect all the cases of thyroid dysfunctions as a large percentage of them are subclinical, ${ }^{9,10}$ which can only be diagnosed by biochemical assessment. As diabetes is a major public health problem, any disorder that may even be weakly associated with it, needs special attention.

Very few studies are there in our country regarding relations of thyroid dysfunctions in type $2 \mathrm{DM}$. There is a growing interest regarding this relation of thyroid status in type $2 \mathrm{DM}$ patients. Controlling hyperglycaemia in the presence of underlying thyroid dysfunction even if it is subclinical poses problem. Correction of thyroid dysfunction may help improving metabolic outcome in type 2 DM patients. In a way thyroid dysfunction and type $2 \mathrm{DM}$ is interlinked, moreover till now there are no internationally accepted guidelines for screening of thyroid dysfunction in type $2 \mathrm{DM}$ patients. This study therefore is designed to know the prevalence of thyroid dysfunctions in recently diagnosed type $2 \mathrm{DM}$ patients.

\section{Aims \& objectives}

1) To assess the clinical features of thyroid hormone dysfunction in diabetes mellitus patients.

2) To evaluate the biochemical thyroid hormone abnormalities in diabetic subjects with or without symptoms of thyroid hormone dysfunction.
3) To assess the prevalence of sub-categorical thyroid dysfunction based on biochemical and/or clinical features.

4) To assess the anti TPO positivity in patients with thyroid dysfunction.

\section{METHODS}

Study area: R.G. Kar Medical College \& Hospital

Study population: The study includes all type 2 diabetics from OPD and IPD of all the departments of R.G. Kar Medical College and Hospital

Study period: 1 year.

Sample size: 60 recently diagnosed type 2 diabetes mellitus patients who do not have any previous thyroid dysfunction.

\section{Exclusion criteria}

1) Type $1 \mathrm{DM}$

2) Gestational DM

3) Steroid induced and fibrocalculous DM

4) Proven thyroid disorder and under treatment.

5) Very sick or critically injured patients.

6) Patients who had undergone surgery of the thyroid gland.

7) Patients who had exposure to radiation of the thyroid gland.

8) Patients of drug-induced hyperglycemia.

\section{Data analysis}

Data analysis has been done in SPSS $19^{\text {th }}$ software Chi square test were used in case of non-parametric value and $\mathrm{p}$ value of $<0.05$ is considered significant.

\section{RESULTS}

It shows the maximum no of recently diagnosed type 2 DM patients belong to into the age group of 36-45 years. Out of total 60 patients 31 belong to this age group $(51.67 \%)$. Least affected age group is above 46 years. Between age group 25-35 years belong 17 patients (28.33\%). Age group range from 26 years to 54 years with mean of 39.90 years for recently diagnosed type 2 DM patients (Table 1). 
Table 1: Age wise distributions of studied population.

\begin{tabular}{|llll|}
\hline Age & Frequency & Percent & Cum. percent \\
\hline 25-35 years & 17 & $28.33 \%$ & $28.33 \%$ \\
\hline 36-45 years & 31 & $51.67 \%$ & $80.00 \%$ \\
\hline 46-55 years & 12 & $20.00 \%$ & $100.00 \%$ \\
\hline Total & 60 & $100.00 \%$ & $100.00 \%$ \\
\hline
\end{tabular}

Out of total 60 patients 37 are Male $(61.7 \%)$ and 23 are Female (38.33\%).

Out of total 60 recently diagnosed type 2 DM patients 44 are Muslim and 16 are Hindu.

It shows that 38 patients out of $60(63.33 \%)$ are in the overweight group (group 2 BMI 25- $29.99 \mathrm{~kg} / \mathrm{m}^{2}$ ), followed by $21.67 \%$ of total patients in the mild obesity range (Table 2 ).

Table 2: Distribution of BMI.

\begin{tabular}{|llll|}
\hline BMI & Frequency & Percent & $\begin{array}{l}\text { Cum. } \\
\text { percent }\end{array}$ \\
\hline $1\left(20-24.99 \mathrm{~kg} / \mathrm{m}^{2}\right)$ & 7 & $11.67 \%$ & $11.67 \%$ \\
\hline $2\left(25-29.99 \mathrm{~kg} / \mathrm{m}^{2}\right)$ & 38 & $63.33 \%$ & $75.00 \%$ \\
\hline $3\left(30-34.99 \mathrm{~kg} / \mathrm{m}^{2}\right)$ & 13 & $21.67 \%$ & $96.67 \%$ \\
\hline $4\left(35-39.99 \mathrm{~kg} / \mathrm{m}^{2}\right)$ & 2 & $3.33 \%$ & $100.00 \%$ \\
\hline Total & 60 & $100.00 \%$ & $100.00 \%$ \\
\hline
\end{tabular}

Average FBS level in recently diagnosed type 2 DM population is $141 \mathrm{mg} / \mathrm{dl}$ and $95 \%$ of the population falls within range of $131 \mathrm{mg} / \mathrm{dl}$ to $151 \mathrm{mg} / \mathrm{dl}$ (Figure 1) and average PPBS in this population is $212 \mathrm{mg} / \mathrm{dl}$ with $95 \%$ of them in between 196-228 mg/dl (Figure 2).

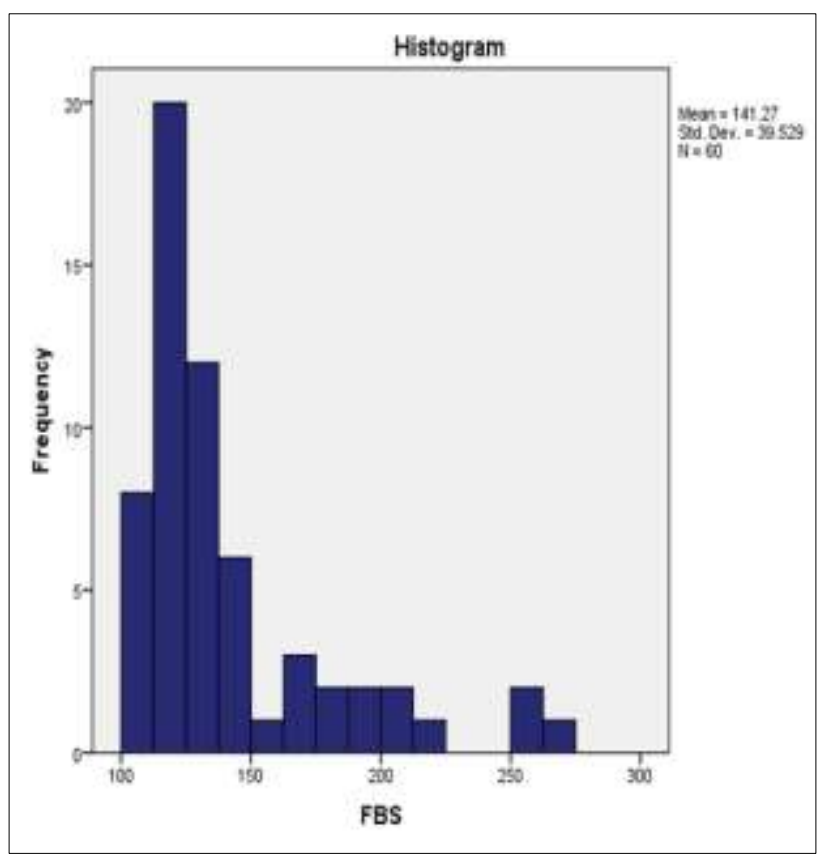

Figure 1: Distribution of fasting blood sugar in the studied population.

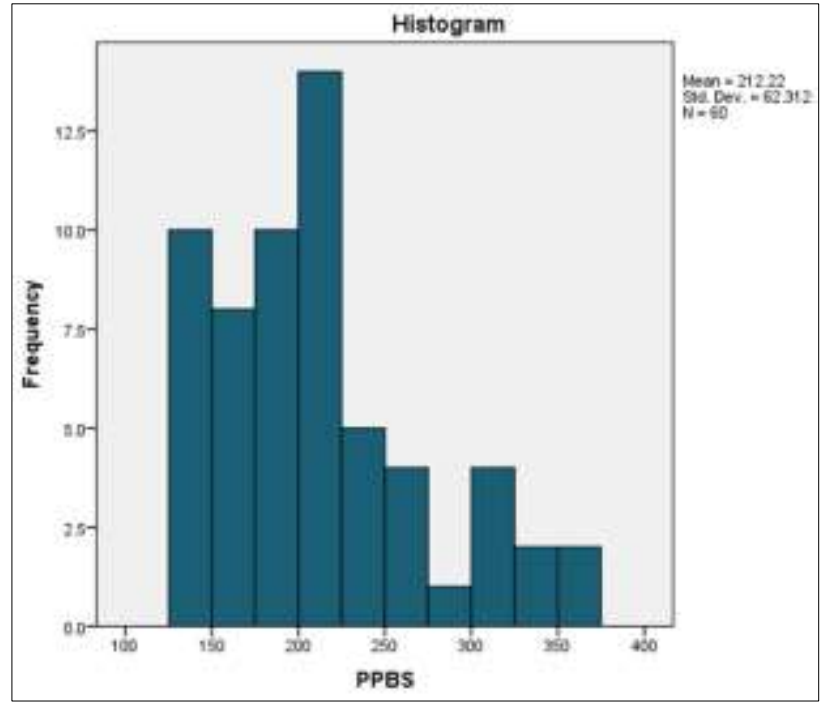

Figure 2: Distribution of post prandial blood sugar level.

HbA1C prevalence in $95 \%$ (2 SD) of population are within $8.02-8.96 \%$, well above the good control $(<7 \%)$ (Figure 3).

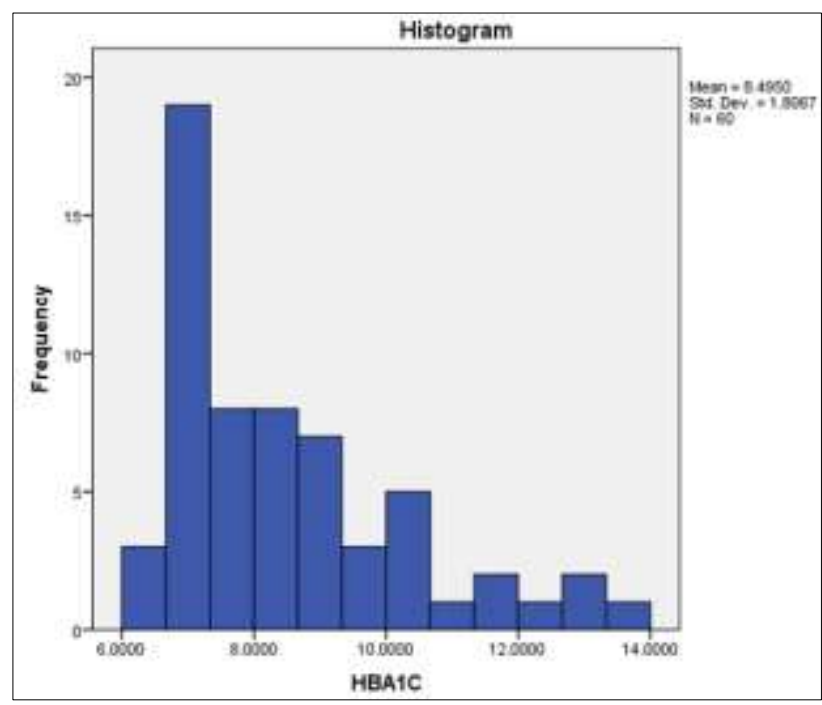

Figure 3: Distribution of $\mathrm{HbA1C}$.

Normal range for FT4 level in blood is $0.7-1.24 \mu \mathrm{g} / \mathrm{dl}$ (standardized for all value). It shows that maximum values are within normal range (Figure 4). Average blood level of FT3 is below normal range (Figure 5). It shows average blood level of TSH is much below normal range (Figure 6).

Study revealed that $75 \%$ of patients (45 out of 60 ) who are newly diagnosed have the biochemical features of thyroid dysfunction. Out of total 60 patients 29 have the biochemical features of Hypothyroidism $(64.44 \%$ of total thyroid dysfunction and $48.3 \%$ of total population) and 16 patients have biochemical features suggestive of hyperthyroidism $(35.65 \%$ of total thyroid dysfunction and 
$26.7 \%$ of total population). Further analysis shows the total prevalence of different subcategorical thyroid dysfunction in recently diagnosed type $2 \mathrm{DM}$ patients as $33.33 \%$ patients show biochemical features of Subclinical hypothyroidism (defined by no symptoms or clinical fetures of hypothyroidism but biochemically TSH level I the range of above $5 \mathrm{mIU} / \mathrm{ml}$ but below $10 \mathrm{mIU} / \mathrm{ml}$ with normal FT4 level), $15 \%$ of patients each for overt hypothyroidism ( either clinical features or Biochemically TSH $>10 \mathrm{mIU} / \mathrm{ml}$ or FT4 below normal), and subclinical hyperthyroidism (only biochemical low level of TSH $<0.34 \mathrm{mIU} / \mathrm{ml}$ in this study) and $11.667 \%$ patients show the features of clinical hyperthyroidism (clinical or FT4 level well above normal range along with low TSH) (Figure 7).

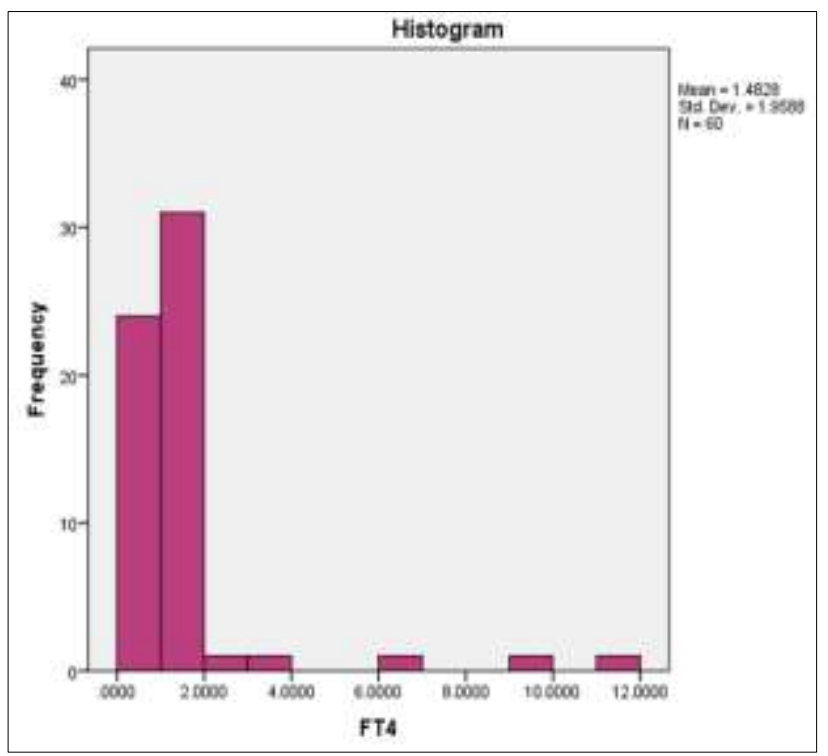

Figure 4: Distribution of free thyroxine (FT4) level $(\mu \mathrm{g} / \mathrm{dl})$.

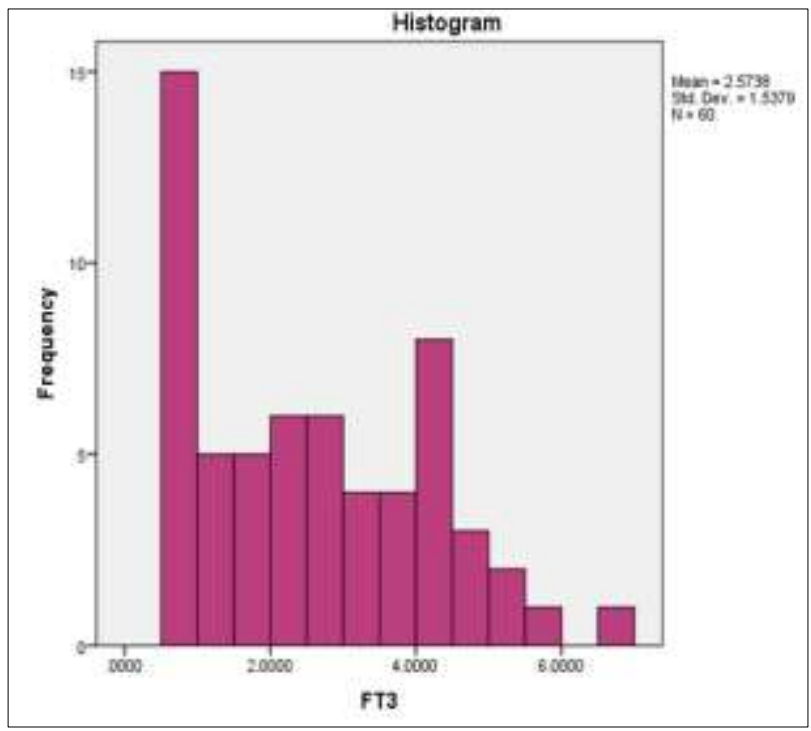

Figure 5: Distribution of FT3 (Free thyroxine 3) level in blood (FT3 in pmol/L).

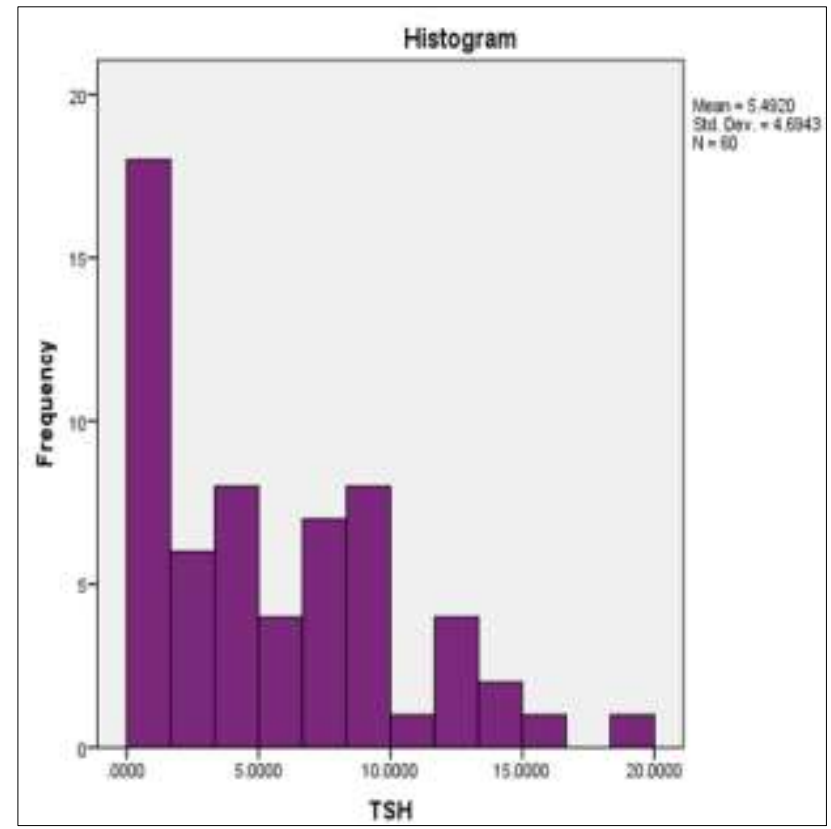

Figure 6: Distribution of TSH (Thyroid stimulating hormone) level in blood (TSH - in $\mathrm{mIU} / \mathrm{ml}$ ).

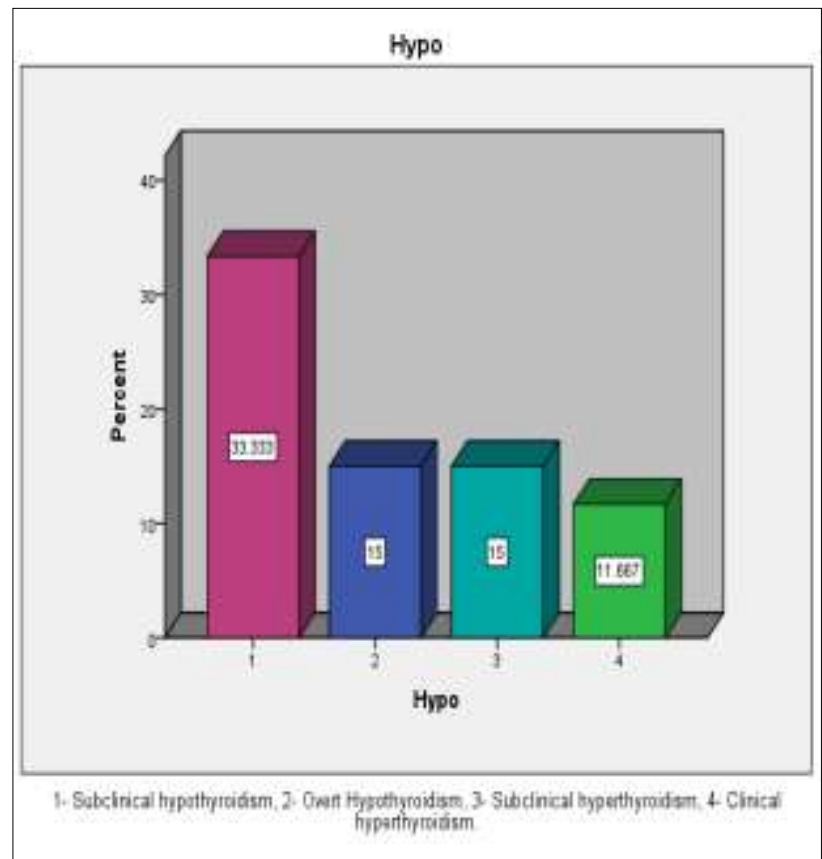

Figure 7: Distribution of hypothyroidism and hyperthyroidism in type $2 \mathrm{DM}$ patients.

Table shows 10 patients out of 45 patients with thyroid dysfunction show anti TPO positivity $(22.22 \%$ of total thyroid abnormality), whereas 35 patients with thyroid dysfunction are anti TPO negative (77.78\%). On the other hand only 1 patient without any thyroid dysfunction shows anti TPO positivity (6.67\%), whereas 14 patients without any thyroid abnormality are anti TPO negative $(93.33 \%)$ (Table 3). 
Table 3: Showing anti TPO positivity in each subcategory of thyroid dysfunction.

\begin{tabular}{|llll|}
\hline \multirow{2}{*}{$\begin{array}{l}\text { Thyroid status } \\
\text { Subclinical }\end{array}$} & Positive & Negative & Total \\
\hline $\begin{array}{l}\text { Subothyroidism } \\
\text { hypoth }\end{array}$ & 4 & 16 & 20 \\
\hline Row\% & $20.00 \%$ & $80.00 \%$ & $100.00 \%$ \\
\hline Col\% & $36.36 \%$ & $32.65 \%$ & $33.33 \%$ \\
\hline $\begin{array}{l}\text { Overt } \\
\text { hypothyroidism }\end{array}$ & 3 & 6 & 9 \\
\hline Row\% & $33.33 \%$ & $66.67 \%$ & $100.00 \%$ \\
\hline Col\% & $27.27 \%$ & $12.24 \%$ & $15.00 \%$ \\
\hline $\begin{array}{l}\text { Subclinical } \\
\text { hyperthyroidism }\end{array}$ & 2 & 7 & 9 \\
\hline Row\% & $22.22 \%$ & $77.78 \%$ & $100.00 \%$ \\
\hline Col\% & $18.18 \%$ & $14.29 \%$ & $15.00 \%$ \\
\hline $\begin{array}{l}\text { Clinical } \\
\text { hyperthyroidism }\end{array}$ & 1 & 6 & 7 \\
\hline Row\% & $14.29 \%$ & $85.71 \%$ & $100.00 \%$ \\
\hline Col\% & $9.09 \%$ & $12.24 \%$ & $11.67 \%$ \\
\hline Euthyroid & 1 & 14 & 15 \\
\hline Row\% & $6.67 \%$ & $93.33 \%$ & $100.00 \%$ \\
\hline Col\% & $9.09 \%$ & $28.57 \%$ & $25.00 \%$ \\
\hline Total & 11 & 49 & 60 \\
\hline Row\% & $18.33 \%$ & $81.67 \%$ & $100.00 \%$ \\
\hline Col\% & $100.00 \%$ & $100.00 \%$ & $100.00 \%$ \\
\hline & & & \\
\hline & & & 7 \\
\hline
\end{tabular}

\section{DISCUSSION}

India is the second most populous country in the world, currently (2013) has an estimated 65.1 million diabetic people, a figure that is set to rise to 109 million by 2035 . $^{11}$ Sequential surveys from India indicate that the prevalence of diabetes has risen steadily since the 1970s. ${ }^{12-15}$ Although methodologic differences hamper comparisons between these studies. There is little reliable information on the prevalence of hyperthyroidism and hypothyroidism in the community. The incidence of hypothyroidism in different communities has varied from $0.6 \%$ to $1.5 \% .^{16}$ Thyroid hormones are insulin antagonists, both insulin and thyroid hormones are involved in cellular metabolism and excess and deficit of any one can result in functional derangement of the other 17. Thyroid disease is a pathological state that adversely affects diabetic control and is commonly found in most forms of DM which is associated with advanced age in type 2 diabetes and autoimmune diseases in type 1diabetes. DM appears to influence thyroid function in two sites; firstly at the level of hypothalamic control of TSH release and secondly at the conversion of T4 to T3 in the peripheral tissue. Marked hyperglycaemia causes reversible reduction of the activity and hepatic concentration of T4-5-deiodinase, low serum concentration of T3, elevated levels of reverse T3 and low, normal, or high level of T4 . A variety of thyroid abnormalities may co-exist and interact with diabetes mellitus. The reported frequency of hyperthyroidism and hypothyroidism in patients with diabetes has varied from $3.2 \%$ to $4.6 \%$ and $0.7 \%$ to $4.0 \%$ respectively. ${ }^{18}$ As early as 1968 it was reported that there exists the association of hypothyroidism in diabetic patients. ${ }^{19}$ Later studies in 1979 emphasized the importance of screening of diabetic patients to identify hypothyroidism. Now it has been found that thyroid disease and both type 1 and type 2 diabetes mellitus are strongly associated and this has important clinical implications for treatment requirements. $^{20}$ Also, diabetes mellitus patients with hypothyroidism are at increased risk for complications like nephropathy.

In our study it is found that maximum no of recently diagnosed type $2 \mathrm{DM}$ patients belong to into the age group of $36-45$ years ( $51.67 \%$ ), followed by $25-35$ years, which is accordance with the studies of Palma et al. $2013 .^{21}$ The mean age of detection of type $2 \mathrm{DM}$ is 39 years in this study. This study reflects much more prevalence in 25-35 years age group compared to The National Urban Diabetes Survey, carried out in six cities in $2001 .^{22}$ But later studies like the Chennai Population Study (CUPS) which has recently revealed alarming rates of incidence of diabetes, shows same time of prevalence in younger age group. ${ }^{23}$

The gender distribution show predominant male involvement which is same like several studies done before regarding epidemiology of type 2 DM. Prevalence is also higher in Muslim population compared to Hindu community, which actually reflects Muslim predominant patients seeking health care in this hospital. It shows average FBS level in recently diagnosed type 2 DM population is $141 \mathrm{mg} / \mathrm{dl}$ and $95 \%$ of the population falls within range of $131 \mathrm{mg} / \mathrm{dl}$ to $151 \mathrm{mg} / \mathrm{dl}$ which is quite higher than recent study from south India (Ghanashyam et al., 2008). ${ }^{24}$ This reflects higher level of abnormal metabolic status in this part of India which might pose more problem in controlling the blood sugar level as well as long term outcomes. The average PPBS in this population is $212 \mathrm{mg} / \mathrm{dl}$ with $95 \%$ of them in between $196-228 \mathrm{mg} / \mathrm{dl}$ which is almost similar to previous study. Distribution of HbA1C shows $95 \%$ (2 SD) of population are within $8.02-8.96 \%$, well above the good control $(<7 \%)$ consistent with Vibha Uppal et al. ${ }^{25}$ Distribution of FT4 level is normal in maximum no of patients whereas that of FT3 is towards lower range of normal value. But TSH level is significantly abnormal reflecting underlying thyroid abnormality in maximum population, which in accordance with Celani et al. ${ }^{26}$ In our study we found a low T3 state with significantly increased fasting blood glucose, HbA1C. Low serum T3 may be due to reduced peripheral conversion of $\mathrm{T} 4$ to $\mathrm{T} 3$ via deiodination reaction. It is known that insulin, an anabolic hormone enhances the levels of FT4 while it suppresses the levels of T3 by inhibiting hepatic conversion of T4-T3. TRH synthesis decreases in diabetes mellitus and also there is loss of nocturnal TSH peak which is responsible for the occurrences of low thyroid hormone levels in some diabetics. In euthyroid individuals with diabetes mellitus, 
the serum T3 levels, basal TSH levels and TSH response to Thyrotropin Releasing Hormone (TRH) all are strongly influenced by the glycemic status. ${ }^{27}$

This study shows that $75 \%$ of diabetic population shows thyroid dysfunction which is much higher than several previous studies. $64.44 \%$ of them are hypothyroid and $35.56 \%$ of them are hyperthyroid. Further analysis shows $33.33 \%$ patients show biochemical features of subclinical hypothyroidism (defined by no symptoms or clinical features of hypothyroidism but biochemically TSH level in the range of above $5 \mathrm{mIU} / \mathrm{ml}$ but below $10 \mathrm{mIU} / \mathrm{ml}$ with normal FT4 level), $15 \%$ of patients each for overt hypothyroidism ( either clinical features or biochemically TSH $>10 \mathrm{mIU} / \mathrm{ml}$ or FT4 below normal), and subclinical hyperthyroidism (only biochemical low level of TSH $<0.34 \mathrm{mIU} / \mathrm{ml}$ with normal FT4 level) and $11.667 \%$ patients show the features of clinical hyperthyroidism (clinical or FT4 level well above normal range along with low TSH). This study shows much higher rate of thyroid dysfunction compared to several previous studies like $1.7 \%$ in Ganz et al., ${ }^{28} 3.6 \%$ in Hecht and Gershberg et al., ${ }^{29} 14.7 \%$ in Perros et al., ${ }^{30} 12.3 \%$ of Greek diabetic patients and $16 \%$ of Saudi diabetic patients and in $12.5 \%$ of type 2 diabetic patients in Jordan. ${ }^{31}$

However this study matches with recent study from south India, which has shown high prevalence of thyroid dysfunction in type $2 \mathrm{DM}$ patients $(21.9 \%$ of subclinical hypothyroidism and of $7.4 \%$ overt hypothyroidism. ${ }^{32}$

A large multi-centered study on pediatric population from 10 states in India has shown higher prevalence of subclinical hypothyroidism $(31.2 \%){ }^{33} \mathrm{~A}$ very high prevalence has also been noted outside India, from Nigeria, Calabar $(46.5 \%)^{34}$ (C. E. J. Udiong, et al.), $51.6 \%$ (Pimenta et al). ${ }^{35}$ and same as from Middle East.

Prevalence of subclinical hypothyroidism is commonest disorder in this study $(33.33 \%)$ which is similar to study by Perez et al. $2011^{36}$ and many other previous studies like Smithson et al., ${ }^{37}$ Suzuki et al. ${ }^{38}$ and Celani et al. ${ }^{39}$

Anti TPO positivity has been found to be positive in $18.33 \%$ of total population which is consistent with most other studies, ${ }^{40} 22.22 \%$ in patients with thyroid dysfunction (most prevalent with subclinical hypothyroidism followed by overt hypothyroidism) and $6.67 \%$ in euthyroid patients. These findings are also consistent with previous study reported by Whitehead et al., Perros et al. ${ }^{41}(13.4 \%)$ and Papazafiropoulou $(12.3 \%)^{42}$

In our study very high prevalence of thyroid dysfunction may be because of only concentrating type 2 DM rather than thinking other diagnosis partly or misreporting by patients. Whatever it is, these significant percentages emphasize that the diabetic patients to be followed up with thyroid profile. The pathophysiology of thyroid dysfunction in diabetes is still unclear. The cause may be due to the complex interaction of common signalling pathways of insulin modulation and feedback mechanism of thyroid hormones. This study did not show any correlation between FBS and/or HbA1C levels and parameters of thyroid profile. This may suggests that absence or minimal role of blood sugar concentration in thyroid dysfunction. Diverse studies support a biologically plausible role for hypothyroidism increasing the risk of atherosclerotic cardiovascular diseases insulin resistance. ${ }^{43}$ Type $2 \mathrm{DM}$ is an independent risk factor for atherosclerotic cardiovascular disease. ${ }^{44}$ So it is important to evaluate diabetic population regarding hypothyroidism whether clinical or sub-clinical, as one condition can worsen the other if left untreated by causing worsening control of diabetes mellitus and causing diverse complications. However it is not clear that treatment of subclinical hypothyroidism is associated with better outcomes or not still it is imperative to screen diabetic population regarding hypothyroidism for better outcomes in overt hypothyroidism as evident from recent Cochrane analysis. Current clinical guidelines recommendations are inconsistent in the detection of thyroid dysfunction in patients with T2DM. So further studies on large scale should be planned to evaluate the magnitude of the disorder.

\section{CONCLUSION}

This study, the first of its kind in Eastern India, showing high prevalence of abnormal thyroid hormone level higher than what is recorded in Europe and US but consistent with Africa.

The high prevalence of abnormal thyroid hormone levels may be due to local environmental factors, high incidence of smoking or may be due to some genetic link. Further studies are necessary to elucidate the cause and the role of abnormal thyroid hormone levels in this population. Additional studies will be needed to determine how frequently thyroid function should be tested in the followup of these patients based on the incidence rates. In our study Primary Hypothyroidism is highly prevalent in patients with T2DM .We recommend the thyroid profile as a routine test in all patients with T2DM in the initial diagnosis and follow up.

\section{Funding: No funding sources}

Conflict of interest: None declared

Ethical approval: The study was approved by the institutional ethics committee

\section{REFERENCES}

1. Alvin C. Powers. Diabetes mellitus. In: Dan L. Longo, Dennis L. Kasper, eds. Harrison's Principle of Internal Medicine. 18th ed. New York: McGrawHill Publication; 2001: 2968.

2. IDF. Diabetes atlas, 2015. Available at: http://www.idf.org/diabetesatlas/5e/regionaloverviews. 
3. Chan JC1, Malik V, Jia W, Kadowaki T, Yajnik CS, Yoon $\mathrm{KH}$, et al. Diabetes in Asia: Epidemiology, risk factors, and pathophysiology. JAMA. 2009 May;301(20):2129-40.

4. Heuck CC, Kallner A, Kanagasabapathy AS, Riesen W. Diagnosis and monitoring of diseases of the thyroid. In: WHO, eds. WHO Report. Geneva: WHO; 2000: 8-9.

5. Perros P, McCrimmon RJ, Shaw G, Frier BM. Frequency of thyroid dysfunction in diabetic patients: value of annual screening. Diabet Med. 1995;12(7):622-7.

6. Cooppan R, Kozak GP. Hyperthyroidism and diabetes mellitus. An analysis of 70 patients. Arch Intern Med. 1980;140(3):370-3.

7. Abrams JJ, Grundy SM, Ginsberg H. Cholesterol metabolism in hypothyroidism and hyperthyroidism in man. J Lipid Res. 1981;22(2):323-38.

8. Perros P, McCrimmon RJ, Shaw G, Frier BM. Frequency of thyroid dysfunction in diabetic patients: value of annual screening. Diabet Med. 1995;12(7):622-7.

9. Gray RS, Irvine WJ, Toft AD, Seth J, Cameron EHD, Clarke BF. Unrecognized thyroid failure in diabetes mellitus. J Clin Lab Immunol. 1979;2:2214.

10. Feely J, Isles TE. Screening for thyroid dysfunction in diabetics. Br Med J. 1979;1(6179):1678.

11. International Diabetes Federation. Diabetes atlas. In: IDF, eds. An Atlas. 6th ed. Belgium: IDF; 2013: 34.

12. Ahuja M. Epidemiological studies on diabetes mellitus in India. In: Ahuja M, eds. Epidemiology of Diabetes in Developing Countries. 1st ed. New Delhi: Interprint; 1979: 29-38.

13. Verma NP, Mehta SP, Madhu S, Mather HM, Keen $H$. Prevalence of known diabetes in an urban Indian environment: the Darya Ganj diabetes survey. $\mathrm{Br}$ Med J (Clin Res Ed). 1986;293:423-4.

14. Ramachandran A, Snehalatha C, Dharmaraj D, Viswanathan M. Prevalence of glucose intolerance in Asian Indians: urban-rural difference and significance of upper body adiposity. Diabetes Care. 1992;15:1348-55.

15. Ramachandran A, Snehalatha C, Kapur A, Vijay V, Mohan V, Das AK, et al. High prevalence of diabetes and impaired glucose tolerance in India: National Urban Diabetes Survey. Diabetologia. 2001;44:1094-101.

16. Feely J, Isles TE. Screening for thyroid dysfunction in diabetics. Br Med J. 1678;1(6179):1979.

17. Sugure DD, McEvoy M, Drury MI. Thyroid disease in diabetics. Postgrad Med J. 1999;58(685):680-4.

18. Shah SN. Thyroid disease in diabetes mellitus. J Assoc Physicians India. 1998:32(12):1057-9.

19. Akbar DH, Ahmed MM, Al-Mughales J. Thyroid dysfunction and thyroid autoimmunity in Saudi type 2 diabetics. Acta Diabetologica. 2006;43(1):14-8.

20. Radetti G, Paganini C, Gentili L, Bernasconi S, Betterle C, Borkenstein M, et al. Frequency of Hashimoto's thyroiditis in children with type 1 diabetes mellitus. Acta Diabetologica. 1995;32(2):121-4.

21. Cátia Cristina Silva Sousa Vergara Palma, Marco Pavesi, Verônica Guedes Nogueira, Eliete Leão Silva Clemente, Maria de Fátima Bevilacqua Motta Pereira Vasconcellos, Luiz Carlos Pereira, Júnior, et al. Prevalence of thyroid dysfunction in patients with diabetes mellitus. Diabetol Metab Syndr. 2013;5:58.

22. Ramachandran A, Snehalatha C, Kapur A, Vijay V, Mohan V, Das AK, et al. High prevalence of diabetes and impaired glucose tolerance in India: National Urban Diabetes Survey. Diabetologia. 2001;44(9):1094-101.

23. Mohan V, Deepa M, Anjana RM, Lanthorn H, Deepa R. Incidence of diabetes and pre - diabetes in a selected urban south Indian population (CUPS19). J Assoc Physicians India. 2008;56:152-7.

24. Ghanshyam Palamaner Subash Shantha, Anita A. Kumar, Vijay Jeyachandran, Deepan Rajamanickam, K. Rajkumar, Shihas Salim, et al. Association between primary hypothyroidism and metabolic syndrome and the role of $\mathrm{C}$ reactive protein: a cross-sectional study from South India. Thyroid Res. 2009;2:2.

25. Uppal V, Vij C, Bedi GK, Vij A, Banerjee BD. Thyroid disorders in patients of type 2 diabetes mellitus. Indian J Clin Biochem. 2013 OctDec;28(4):336-41.

26. Celani MF, Bonati ME, Stucci N. Prevalence of abnormal thyrotropin concentrations measured by a sensitive assay in patients with type 2 diabetes mellitus. Diabetes Res. 1994;27:15-25.

27. Schlienger JL, Anceau A, Chabrier G, North ML, Stephan F. Effect of diabetic control on the level of circulating thyroid hormones. Diabetologia. 1982;22:486-8./// Bartalena L, Cossu E, Grasso L, Velluzzi F, Loviselli A, Cirillo R, et al. Relationship between nocturnal serum thyrotropin peak and metabolic control in diabetic patients. J Clin Endocrinol Metab. 1993;76(4):983-7.

28. Ganz K, Kozak GP. Diabetes mellitus and primary hypothyroidism. Arch Intern Med. 1974;134:430-2.

29. Hecht A, Gershberg H. Diabetes mellitus and primary hypothyroidism. Metabolism. 1968;17:10813.

30. Perros P, McCrimmon RJ, Shaw G, Frier BM. Frequency of thyroid dysfunction in diabetic patients: value of annual screening. Diabet Med. 1995;12:622-7.

31. Hage M, Zantout M, Azar S. Thyroid disorders and diabetes mellitus. J Thyroid Res. 2011;2011:439463.

32. Shantha GP1, Kumar AA, Jeyachandran V, Rajamanickam D, Rajkumar K, Salim S, et al. Association between primary hypothyroidism and metabolic syndrome and the role of $\mathrm{C}$ reactive protein: a cross-sectional study from South India. Thyroid Res. 2009;2:2. 
33. Toteja GS, Singh P, Dhillon BS, Saxena BN. Iodine deficiency disorders in 15 districts of India. Indian J Pediatr. 2004;71(1):25-8.

34. Udiong CEJ, Udoh AE, Etukudoh ME. Evaluation of thyroid function in diabetes mellitus in Calabar, Nigeria. Indian J Clin Biochem. 2007;22(2):74-8.

35. Pimenta WP, Mazeto GM, Callegaro CF, Shibata SA, Marins LV, Yamashita S, et al. Thyroid disorders in diabetic patients. Arq Bras Endocrinol Metabol. 2005;49:234-40.

36. Hector-Eloy Tamez-Perez, Esteban Martı'nez, Dania L Quintanilla-Flores, Alejandra L TamezPeña, Hugo Gutiérrez-Hermosillo, Enrique Díaz de León-González. The rate of diagnosed primary hypothyroidism in diabetic patients is greater than in the non-diabetic population. An observational study. Med Clin (Barc). 2011;1:1-4.

37. Smithson MJ. Screening for thyroid dysfunction in a community population of diabetic patients. Diabet Med. 1998;15(2):148-50.

38. Suzuki J, Nanno M, Gemma R, Tanaka I, Taminato $\mathrm{T}$, Yoshimi T. The mechanism of thyroid hormone abnormalities in patients with diabetes mellitus. Nippon Niabunpi Gakki Zasshi. 1994;7(4):465-70.

39. Celani MF, Bonati ME, Stucci N. Prevalence of abnormal thyrotropin concentrations measured by a sensitive assay in patients with type 2 diabetes mellitus. Diabetes Res. 1994;27(1):15-25.

40. Henry M. Kronenberg. Anti TPO positivity. In: Shlomo Melmed, Kenneth S. Polonsky, P. Reed Larsen, eds. Williams Textbook of Endocrinology. 11th ed. Philadelphia: Saunders; 2008: 2011, Table 10-14.

41. Perros P. McCrimmon RJ, Shaw G, Frier BM. Frequency of thyroid dysfunction in diabetic patients: value of annual screening. Diabet Med. 1995;12(7):622-7.

42. Papazafiropoulou A. Prevalence of thyroid dysfunction among Greek type 2 diabetic patients attending an outpatient clinic. J Clin Med Res. 2010;2(2):75-8.

43. Neves C, Alves M, Medina JL, Delgado JL. Thyroid diseases, dyslipidemia and cardiovascular pathology. Rev Port Cardiol. 2008;27:1211-36.

44. Duntas LH, Orgiazzi J, Barbant G. The interface between thyroid and diabetes mellitus. Clin Endocrinol. 2011;75:1-9.

Cite this article as: Mukherjee S, Datta S, Datta P, Mukherjee AK, Maisnam I. A study of prevalence of primary hypothyroidism in recently diagnosed type 2 diabetes mellitus in a tertiary care hospital. Int J Sci Rep 2015;1(2):105-12. 